ПОЛОЖИТЕЛЬНЫЙ ОПЫТ ВЕДЕНИЯ И РОДОРАЗРЕШЕНИЯ БЕРЕМЕННОЙ С ПОСТТРОМБОФЛЕБИТИЧЕСКИМ СИНДРОМОМ И ТЭЛА ВО ВРЕМЯ БЕРЕМЕННОСТИ

(C) С.М. Бочарова, Д.В. Анфалов

Рязанский государственный медицинский университет имени академика И.П. Павлова, г. Рязань, Российская Федерация

Ведение беременности и родов у женщин с венозными тромбоэмболическими осложнениями (ВТЭО) является одной из наиболее актуальных проблем современного акушерства. Будучи редким осложнением нормальной беременности, ВТЭО занимают одно из ведущих мест среди причин материнской смертности. По последним данным, венозный тромбоз регистрируется у $0,42 \%$ беременных и $3,5 \%$ родильниц. В подавляющем большинстве случаев он осложняется ТЭЛА, которая, практически, для каждой третьей женщины в отсутствии адекватного лечения заканчивается летальным исходом.

Как известно, физиологическая беременность увеличивает риск развития тромбоэмболических осложнений в 4-6 раз. В это время прогрессивно увеличивается количество прокоагуляционных факторов, снижается активность антикоагулянтной и фибринолитической систем. Значительно уменьшается скорость венозного кровотока, главный образом, за счет нарушения венозного оттока под давлением беременной матки. Таким образом, беременность является состоянием, при котором тромбоэмболические осложнения могут развиваться внезапно, даже каких-либо предшествующих факторов риска.

Каждый случай ВТЭО представляет собой серьезную проблему для врачей акушеровгинекологов. На сегодняшний день в литературе описано лишь несколько случаев применения тромболитической терапии у беременных. Отсутствует доказательная база безопасности препаратов тромболизиса для плода. Не разработано четких рекомендаций по ведению и тактике родоразрешения данной категории беременных, и вопрос о том, как вести беременность в такой ситуации, все еще остается предметом дискуссий.

В данной статье мы хотим поделиться уникальным опытом ведения беременности и родов у женщины с посттромбофлебитическим синдромом (ПТФС) и ТЭЛА во время беременности.

Ключевые слова: тромбоэмболические осложнения, беременность, роды.

\title{
THE POSITIVE EXPERIENCE OF MATERNITY AND CHILDBIRTH WITH POSTTHROMBOPHLEBITIC SYNDROME AND PULMONARY EMBOLISM DURING PREGNANCY
}

\author{
(C) S.M. Bocharova, D.V. Anfalov
}

Ryazan State Medical University, Ryazan, Russian Federation

Maternity and childbirth with venous thromboembolic complications (VTC) is one of the most urgent problems of modern obstetrics. Being a rare complication of normal pregnancy, VTC occupy one of the leading places among the causes of maternal mortality. According to the latest 
data, venous thrombosis occurs in approximately $0.42 \%$ of pregnant women and $3.5 \%$ of puerperants. In the overwhelming majority of cases, it is complicated by pulmonary embolism, which in the absence of adequate treatment, leads to death of every third woman.

The natural physiology of pregnancy increases the risk of thromboembolic complications by 4-6 times. There is a progressive increase in the content of procoagulant factors, decrease in the activity of the anticoagulant and fibrinolytic system. The rate of venous blood flow significantly decreases, mainly due to the disruption of venous outflow under the pressure of the pregnant uterus. Thus, pregnancy is a condition, in which thromboembolic complications can develop suddenly, without any previous risk factors.

Every case of VTC is a serious problem for doctors. Only few cases of applying thrombolytic therapy in pregnant woman are described in the literature. There is no evidence base for the safety of thrombolysis drugs for the fetus. There are no clear guidelines for the management and tactics of delivery of this category of pregnant women and the question, how to lead the pregnancy in such a situation, is still a matter of debate.

We want to share a unique experience in the management of pregnancy and childbirth of the woman with postthrombophlebitic syndrome and pulmonary embolism during pregnancy.

Keywords: thromboembolic complications, pregnancy, childbirth.

Ведение беременности и родов у женщин с венозными тромбоэмболическими осложнениями (ВТЭО) является одной из наиболее актуальных проблем современного акушерства. По исследованиям ВО3 тромбозы являются причиной материнской смерти в 3\% [1]. В РФ этот показатель достигает 7\% [2]. По последним данным венозный тромбоз встречается приблизительно у $0,42 \%$ беременных и у $3,5 \%$ родильниц [3]. В 90\% случаев тромбоз глубоких вен осложняется ТЭЛА [4], которая у 30\% женщин в отсутствии адекватного лечения приводит к летальному исходу [5].

Физиологическая беременность увеличивает риск развития тромбоэмболических осложнений в 4-6 раз [5]. Естественному течению беременности присущи все три компонента триады Вирхова: замедление тока крови, повреждение стенки сосуда, изменение реологических свойств крови [5]. Наблюдается прогрессивное увеличение содержания прокоагуляционных факторов (VIII, VII, V, X, XII, VII, фибриногена), снижение активности антикоагулянтной системы за счет развития резистентности к активированному протеину $\mathrm{C}$ (APC) и снижения уровня протеина $\mathrm{S}$ на $40 \%$. Торможение фибринолиза при беременности связано с продукцией плацентой ингибитора активатора плазминогена 2-го типа (PAI-2), а также вследствие трехкратного увеличения экспрессии PAI-1 на эндотелии. Состояние гипофибринолиза усугубляется повышением уровня антиплазмина и ингибитора фибринолиза, активируемого тромбином (TAFI). Другим фактором, способствующим формированию протромботического потенциала, является венозный стаз, который начинает формироваться в конце первого триместра беременности. К 25-29-й неделе скорость венозного кровотока уменьшается на 50\%. Наибольшей степени венозный стаз достигает при сроке беременности 36 недель, а исходная скорость кровотока восстанавливается лишь через 6 недель после родоразрешения. При беременности венозное давление в среднем повышается на 10 мм рт. ст., чему способствует нарушение венозного оттока под давлением беременной матки и увеличение кровотока по маточной и внутренним подвздошным венам. Вследствие изменения гормонального фона при беременности, в условиях избытка гестагенов, происходит уменьшение тонуса вен. Все это также способствует развитию стаза. Кроме того, как при оперативных родах, так и при естественном родоразрешении, происходит повреждение тазовых вен [5-10]. Таким образом, беременность является состоянием, при котором тромбоэм- 
болические осложнения могут развиваться внезапно, без каких-либо предшествующих факторов риска [5].

Каждый случай венозных тромбоэмболических осложнений представляет собой серьезную проблему для акушеровгинекологов. На сегодняшний день в литературе описано лишь несколько случаев применения тромболитической терапии у беременных. Отсутствует доказательная база безопасности препаратов тромболизиса для плода $[11,12]$. Не разработано четких рекомендаций по ведению и тактике родоразрешения данной категории беременных, и вопрос о том, как вести беременность в такой ситуации, все еще остается предметом дискуссий.

Клинический случай. Пациентка Ф, 33 года, поступила 19.09.2017 г. в родильный дом №4 г. Рязань для планового родоразрешения путем кесарева сечения с диагнозом: беременность 3, роды 2, тазовое предлежание плода, посттромбофлебитический синдром (ПТФС) левой нижней конечности, состояние после ТЭЛА (29.06.17), тромболизис Актилизе (29.06.17) эффективный.

При поступлении общее состояние удовлетворительное. Сознание ясное. В легких дыхание везикулярное, хрипов нет. ЧДД 18 в мин. Тоны сердца ясные, ритмичные, АД 120/80 мм рт. ст., ЧСС 72 уд/мин. Окружность живота 116 см. Высота стояния дна матки 33 см. Рост 189 см, вес 105 кг. Сердцебиение плода ясное, ЧСС 130 уд/мин, тазовое предлежание, головка над входом в малый таз.

Настоящая беременность 3 , роды 2. Первая беременность в 2009г. Течение без особенностей, роды физиологические, плод жив. Вторая беременность в 2013г. завершилась самопроизвольным абортом на сроке 21-22 недель.

В июне 2017 г. беременная находилась на стационарном лечении в ГБУ РО ОКПЦ г. Рязани с диагнозом ложные схватки на сроке 24-25 недель. Утром 29.06.2017 г. потеряла сознание, почувствовала одышку, сердцебиение, боли в области левой икроножной мышцы. При объективном обследовании общее состояние оставалось тяжелым. В легких дыхание везикулярное. ЧДД 22 в мин. Тоны сердца приглушены, ритм правильный. АД 70/50 мм рт. ст., ЧСС 122 уд/мин. Левая голень и бедро отечны, икроножная мышца болезненна при пальпации. На ЭКГ перегрузка правых отделов сердца. По данным лабораторных тестов: фибриноген 3,8 г/л, тромбиновое время - 10,5 с, АЧТВ - 37,0 c, МНО - 1,45. Переведена в условиях реанимационной бригады скорой медицинской помощи в отделение сосудистой хирургии ГБУ РО ОККД г. Рязани, где диагностирована массивная ТЭЛА с объемом поражения до 90\%, легочная гипертензия, окклюзивный тромбоз левой подколенной вены. Была проведена тромболитическая терапия Актилизе (100 мг) по схеме. После курса антикоагулянтной (Клексан $-1,0 * 2$ $\mathrm{p} /$ д) и антибактериальной терапии (Цефтриаксон 1,0 в/в струйно №5) была выписана в удовлетворительном состоянии с рекомендациями наблюдения сосудистого хирурга ежемесячно и приемом Клексана п/к 1,0*2 p. На фоне проводимого лечения отмечалась положительная динамика, беременность прогрессировала.

После госпитализации в родильный дом были проведены контрольные исследования. УЗИ сердца (20.09.2017): дилатация полости правого предсердия и желудочка, признаков легочной гипертензии нет. УЗДС вен левой нижней конечности (19.09.2017): подколенная вена проходима, представлена одним стволом, большеберцовые вены проходимы. Лабораторные тесты (19.09.2017): эритроциты 4,2*10 12 /л, тромбоциты - $198 * 10^{9} /$ л, гемоглобин - 118 г/л, протромбин - 0,89, фибриноген - 4,42, АЧТВ - 28 с. По данным УЗИ плода (20.09.2017): беременность акушерским сроком 36 недель, патологии со стороны плода не отмечается, соответствует сроку гестации. Плод в тазовом предлежании. Беременная готовилась к проведению планового кесарева сечения на 37 недель гестации, однако за несколько дней до операции на контроль- 
ном УЗИ плода была обнаружена смена предлежания плода на головное.

Для определения дальнейшей тактики ведения беременной был собран консилиум врачей в составе акушеровгинекологов, сосудистых хирургов, кардиологов. Были даны следующие рекомендации: Клексан 0,4*1 p/д - отменить за 12 часов до родоразрешения, эластическая компрессия вен нижних конечностей, родоразрешение в эластических бинтах, возобновление приема Клексана в той же дозе до 6 недель. Контрольное УЗДС вен нижних конечностей, консультация сосудистого хирурга через 6 недель. Роды вести через естественный родовой путь.

2.10.17 г. с регулярной родовой деятельностью беременная переведена в предродовую палату. Прием Клексана был отменен за 24 часа до родов. Начало родовой деятельности 9:20. Время излития околоплодных вод 11:50. Полное открытие 14:50, начало потуг 15:30. Длительность безводного промежутка 3 ч. 45 мин. В 16:20 переднем виде затылочного предлежания родился здоровый мальчик массой 3590г. с оценкой 7-9 баллов по шкале Апгар. Принятие родов проводилось на фоне адекватного обезболивания, контроля гемостаза, эластической компрессии вен нижних конечностей. Общая кровопотеря в родах составила 250 мл. Показатели крови после родов: время свертывания 4-6 с, тромбоциты - 205*10\%/л, гематокрит $-33 \%$, гемоглобин - 121 г/л, фибриноген - 4,0, протромбин - 0,9, АЧТВ - 24 с. Матка плотная, сократилась. Переведена в послеродовую палату.
Прием Клексана возобновлен с 6:00 3.10.17 г. в дозировке $0,4 * 1$ p/д и проведен ежедневный контроль показателей крови. Первые сутки: время свертывания - 4-5 с, тромбоциты - 202*109/л, гематокрит $34 \%$, гемоглобин - 123 г/л, фибриноген 4,07, протромбин - 0,91, АЧТВ - 24 с. Третьи сутки: время свертывания - 4-5 с, тромбоциты - 204*109/л, гематокрит $34 \%$, гемоглобин - 123 г/л, фибриноген 4,0, протромбин - 0,89, АЧТВ - 23 с.

На 4 сутки женщина выписана в удовлетворительном состоянии.

\section{Заключение}

Возникновение ВТЭО было непосредственно связано с беременностью. Об этом можно судить по отсутствию в анамнезе женщины указаний на заболевания со стороны сердечно-сосудистой системы и другие факторы риска.

Проведенная тромболитическая терапия оказалась эффективной и безопасной для матери и плода. Тромболизис позволил благополучно завершить беременность.

В ведении данной категории беременных необходим интегрированный подход врачами смежных специальностей. Благодаря совместным действиям акушеровгинекологов, кардиологов, сосудистых хирургов удалось разработать индивидуальный план ведения беременности и родов и, а главное, сохранить жизнь и здоровье сразу двух человек, матери и ребенка.

\section{Дополнительная информация}

Конфликт интересов: отсутствует.

Этика. В исследовании использованы данные пациентки в соответствии с подписанным информированным согласием.

\section{Литература}

1. Lale S., Chou D., Gemmill A., et al. Global causes of maternal death: a WHO systematic analysis // Lancet Global Health. 2014. Vol. 2, №6. P. 323-333.

2. Байбарина Е.Н., Филлипов О.С., Гусева Е.В., и др. Результаты конфиденциального аудита материнской смертности в РФ в 2015 году. Методическое письмо. М.; 2016. С. 56-62.

3. Смирнова Т.А., Климантович А.И., Дейчик Д.А. Тромбоэмболические осложнения во вре- мя беременности и в послеродовом периоде // Медицинский журнал. 2012. Т. 2, №40. С. 106-112.

4. Ассоциация флебологов России. Всероссийское общество хирургов. Российские клинические рекомендации по диагностике, лечению и профилактике венозных тромбоэмболических осложнений // Флебология. 2015. Т. 9, №2. С. 5-7.

5. Акиньшина С.В., Бицадзе В.О. Тромбоэмболия легочной артерии в акушерской практике // Медицинский совет. 2017. №13. С. 94-106. 
6. James A.H. Thrombosis in pregnancy and maternal outcomes // Birth Defects Res. C. Embryo Today. 2015. Vol. 105, №3. Р. 159-166.

7. Пересада О.А. Репродуктивное здоровье женщин. М.: МИА; 2009.

8. Макацария А.Д., ред. Тромбогеморрагические осложнения в акушерско-гинекологической практике. М.: МИА; 2011.

9. Доброхоротова Ю.Э., Щеголев А.А., ред. Тромботические состояния в акушерской практике. М.: ГЭОТАР-Медиа; 2010.

10. Зеленко Е.Н., Смирнова Л.А., Змачинский В.А. Тромбоэмболические осложнения в акушерской практике. Мн: БелМАПО; 2010.

11. Шакурова Е.Ю., Ястребов М.А. Случай успешного тромболизиса при массивной тромбоэмболии легочной артерии у беременной // Гинекология. 2016. Т. 18, №6. С. 61-62.

12. Агапов А.П., Сучков И.А., Рябков А.Н. Прямые пероральные антикоагулянты в лечении пациентов с тромбозом глубоких вен нижних конечностей // Наука молодых (Eruditio Juvenium). 2016. T. 4, №2. C. 147-157.

\section{References}

1. Say L, Chou D, Gemmill A, et al. Global causes of maternal death: a WHO systematic analysis. Lancet Global Health. 2014;2(6):323-33. doi:10.1016 /S2214-109X(14)70227-X

2. Bajbarina EN, Fillipov OS, Guseva EV, et al. Rezul'taty konfidencial'nogo audita materinskoj smertnosti v Rossijskoj Federacii v 2015 godu. Metodicheskoe pis'mo. Moscow; 2016:56-62. (In Russ).
3. Smirnova TA, Klimantovich AI, Dejchik DA. Tromboembolicheskie oslozhneniya vo vremya beremennosti i v poslerodovom periode. Medicinskij zhurnal. 2012;2(40):106-12. (In Russ).

4. The All-Russian Society of Surgeons. Russian clinical guidelines for the diagnosis, treatment and prevention of venous thromboembolic complications (VTEO). Phlebology. 2015;9(2):5-7. (In Russ).

5. Akinshina SV, Bitsadze VO. Pulmonary artery embolism in obstetric practices. Medical Council. 2017;13:94-106. (In Russ). doi:10.21518/2079701X-2017-13-94-108

6. James AH. Thrombosis in pregnancy and maternal outcomes. Birth Defects Res C Embryo Today. 2015;105(3):159-66. doi:10.1002/bdrc.21106

7. Peresada OA. Reproduktivnoe zdorov'e zhenshchin. Moskow: MIA; 2009. (In Russ).

8. Makacariya AD, ed. Trombogemorragicheskie oslozhneniya $v$ akushersko-ginekologicheskoj praktike. Moskow: MIA; 2011. (In Russ).

9. Dobrohorotova YuE, Shchegolev AA, ed. Tromboticheskie sostoyaniya $v$ akusherskoj praktike. Moskow: GEOTAR-Media; 2010. (In Russ).

10. Zelenko EN, Smirnova LA, Zmachinskij VA. Tromboembolicheskie oslozhneniya $v$ akusherskoj praktike. Minsk: BelMAPO; 2010. (In Russ).

11. Shakurova EYu, Yastrebov MA. A case of successful thrombolysis in massive pulmonary embolism in pregnancy. Gynecology. 2016;18(6): 61-2. (In Russ).

12. Agapov AB, Suchkov IA, Ryabkov AN. Direct oral anticoagulants in patients with deep venous thrombosis of lower extremities.Science of the young.2016;4(2):147-57. (In Russ).

\section{Информация об авторах [Authors Info]}

Бочарова Светлана Михайловна - студентка 6 курса 14 группы лечебного факультета, Рязанский государственный медицинский университет им. акад. И.П. Павлова, г. Рязань, Российская Федерация. e-mail: prettyfifa@yandex.ru SPIN: 5978-2507, ORCID ID: 0000-0002-8924-9990.

Svetlana M. Bocharova - 6-year student at the medical faculty, Ryazan State Medical University, Ryazan, Russian Federation.

e-mail: prettyfifa@yandex.ru

SPIN: 5978-2507, ORCID ID: 0000-0002-8924-9990.

Анфалов Денис Владимирович - ассистент кафедры акушерства и гинекологии, Рязанский государственный медицинский университет им. акад. И.П. Павлова, г. Рязань, Российская Федерация.

SPIN: 2568-6434, ORCID ID: 0000-0001-5807-4780.

Denis V. Anfalov - teaching assistant at Obstetrics and Gynecology Department, Ryazan State Medical University, Ryazan, Russian Federation. SPIN: 2568-6434, ORCID ID: 0000-0001-5807-4780.

Цитировать: Бочарова С.М., Анфалов Д.В. Положительный опыт ведения и родоразрешения беременной с посттромбофлебитическим синдромом и тэла во время беременности // Наука молодых (Eruditio Juvenium). 2018. Т. 6, №3. C. 400-404. doi:10.23888/HMJ201863400-404

To cite this article: Bocharova SM, Anfalov DV. The positive experience of maternity and childbirth with postthrombophlebitic syndrome and pulmonary embolism during pregnancy. Science of the young (Eruditio Juvenium). 2018;6(3):400-4. doi:10.23888/HMJ201863400-404 